\title{
DISTAL 14q TRISOMY SYNDROME IN TWO SIBLINGS: FURTHER DELINEATION OF ITS PHENOTYPE
}

\author{
Yoshiharu WaKita, ${ }^{1}$ Kouji Narahara, ${ }^{1}$ Kiyoshi KikKawa, ${ }^{1}$ \\ Hiroshi Namba, ${ }^{1}$ Kei Hiramoto, ${ }^{1}$ Katuto Eguchi, ${ }^{2}$ \\ Tunenori Matsubara, ${ }^{1}$ and Hiroshi Kimoto ${ }^{1}$ \\ Deparments of ${ }^{1}$ Pediatrics and ${ }^{2}$ Obstetrics, Okayama University School \\ of Medicine, Okayama 700, Japan
}

\begin{abstract}
Summary We describe two siblings with distal $14 \mathrm{q}$ trisomy resulting from a maternal translocation $\mathrm{t}(5 ; 14)(\mathrm{p} 15.33 ; \mathrm{q} 31.2)$ : a male newborn infant who died at the age of 1 month and a prenatally diagnosed male fetus. They showed almost identical phenotypic abnormalities. Review of the literature suggests the occurrence of a distal $14 q$ trisomy syndrome, which is clinically characterized by mental retardation, growth failure, frontal bossing, facial asymmetry, hypertelorism, sparse eyebrows and eyelashes, short prominent nose, cupid bow upperlip, micrognathia, and low-set and posteriorly rotated ears. It seems likely that triplication of the segment $14 \mathrm{q} 32.1 \rightarrow \mathrm{qter}$ is critical for clinical manifestation of this syndrome.
\end{abstract}

Key Words chromosome 5, chromosome 14, distal 14q trisomy syndrome, prenatal diagnosis

\section{INTRODUCTION}

Distal trisomy $14 \mathrm{q}$ is less frequently seen than proximal $14 \mathrm{q}$ trisomy, which has been established as a distinct clinical entity (de Grouchy and Turleau, 1984). At least 19 cases with distal $14 \mathrm{q}$ trisomy have been reported so far. Although delineation of a distal $14 \mathrm{q}$ trisomy syndrome has been attempted (Turleau et al., 1983; Sklower et al., 1984), it still remains open whether or not a distal $14 \mathrm{q}$ trisomy is associated with a well-defined clinical syndrome. In this paper, we describe two additional siblings with distal $14 \mathrm{q}$ trisomy resulting from a maternal translocation $\mathrm{t}(5 ; 14)(\mathrm{p} 15.33 ; \mathrm{q} 31.2)$. Comparison of the clinical features of the present cases with those of the previously reported cases indicates that distal $14 \mathrm{q}$ trisomy is a clinically recognizable syndrome.

Received July 18, 1988; revised version received August 11, 1988; Accepted August 11, 1988 


\section{CASE REPORTS}

Case 1. The patient, a male newborn infant, was the first child of healthy nonconsanguineous parents. The mother and father were 28 and 32 years old, respectively, at the time of the child's birth. There was no family history of spontaneous abortions, mental retardation or congenital anomalies. $\mathrm{He}$ was delivered by caesarean section at the 35 th gestational week because of placenta previa. The birth weight was $1,495 \mathrm{~g}$, and the body length was $38.5 \mathrm{~cm}$. The Apgar scores were both 8 at 1 and $5 \mathrm{~min}$ of age. Physical examination showed a preterm, small-fordates baby with various phenotypic abnormalities. He had an odd facial appearance, consisting of facial asymmetry (right-sided hypotrophy), frontal bossing, hypertelorism, cloudy left cornea, narrow right palpebral fissure, sparse eyebrows and eyelashes, short prominent nose, cupid bow upperlip, and micrognathia (Fig. 1). The ears were low-set and malformed, with prominent antihelices and atresia of both external auditory canals. There was pigeon breast, overlapping of fingers, clinodactyly of the 5th fingers, and prominent calcaneus. A small penis and severe muscular hypotonia were also noticed. Laboratory investigations including complete blood count, blood biochemistry and urinalysis yielded normal results. The baby failed to thrive and died of septicemia at the age of 1 month. Autopsy showed thymic hypoplasia and a patent foramen ovale but no other internal malformations.

Case 2. The mother became pregnant one and a half years after the death of case 1. Amniocentesis was carried out at the 17 th gestational week, and chromosome analysis of an amniotic cell culture revealed an unbalanced chromosomal abnormality. The parents elected to terminate the pregnancy. This male fetus was

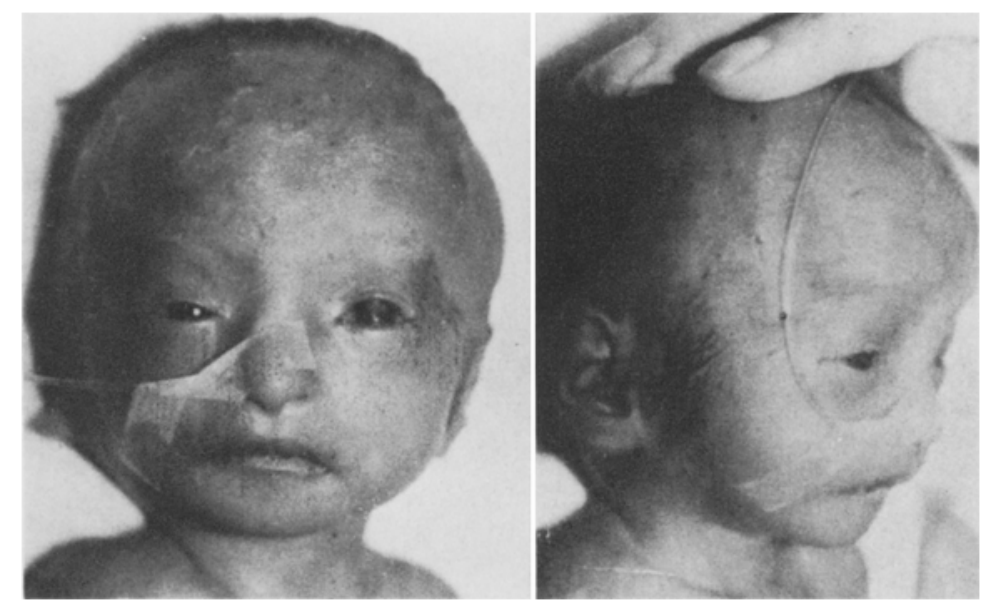

Fig. 1. Case 1 at the age of one month. 


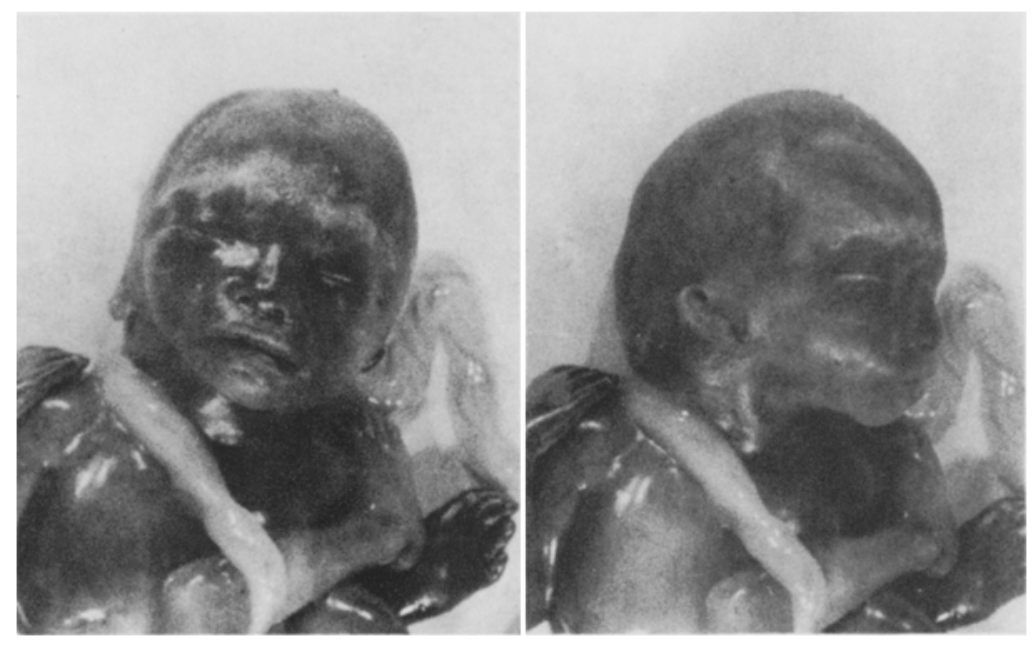

Fig. 2. Case 2 aborted at the 20th gestational week.

aborted at the 20th gestational week by prostaglandin induction. The crown-to-heel length was $23.8 \mathrm{~cm}$, and the weight was $194 \mathrm{~g}$. The phenotypic features were similar to those of case 1 except for absence of corneal opacity and atresia of the external auditory canals (Fig. 2). On the other hand, right pes equinovarus was seen in this fetal case. Autopsy did not show any internal malformation.

\section{CYTOGENETIC FINDINGS}

Cytogenetic analysis was performed on cultured peripheral blood lymphocytes of case 1 and the parents and on cultured amniotic cells and skin fibroblasts of case 2. Chromosomes were stained by GTG-banding. Prophasic cells in lymphocyte cultures were collected according to the method of Ikeuchi and Sasaki (1979).

Chromosome analysis of case 1 showed an extra amount of chromosome material on the short arm of chromosome 5. The father had normal chromosomes, while the mother was found to be carrying a balanced reciprocal translocation between chromosomes 5 and 14 . The high-resolution banding study revealed the breakpoints at 5p15.33 and 14q31.2 (Fig. 3). The same karyotypic abnormality as seen in case 1 was detected in the cultured amniotic cells of case 2. This abnormality was subsequently confirmed on the fibroblast culture obtained from the skin of the aborted fetus. Karyotypes of both cases were designated as $46, \mathrm{XY},-5$, $+\operatorname{der}(5), \mathrm{t}(5 ; 14)(\mathrm{p} 15.33 ; \mathrm{q} 31.2)$ mat.

\section{DISCUSSION}

The present cases had trisomy for $14 \mathrm{q} 31.2 \rightarrow$ qter derived from an adjacent I segregation of the maternal reciprocal translocation, $t(5 ; 14)(\mathrm{p} 15.33 ; \mathrm{q} 31.2)$. Since 


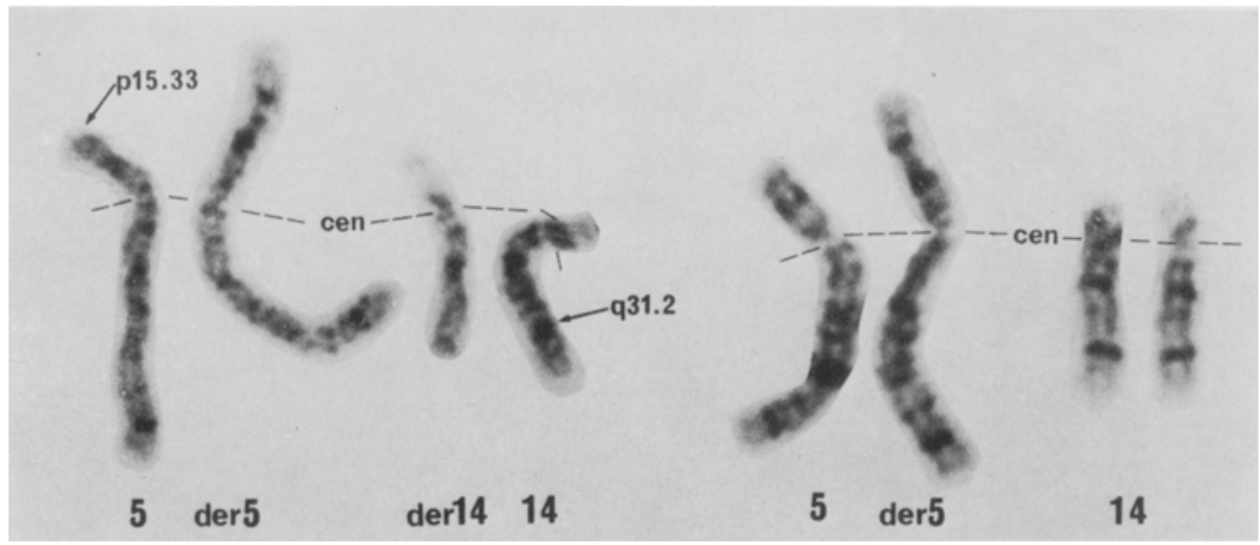

(A)

(B)

Fig. 3. Partial karyotypes of the mother (A) and the case 2(B). Arrows indicate breakpoints of the translocation.

the breakpoint is located in the terminal band of the short arm of chromosome 5, monosomy for $5 \mathrm{p}$ is negligible. Clinical features of the two cases were distinct and resembled each other. The phenotypic discordance in certain features between the two cases may be accounted for by the development of such abnormalities in late fetal life or the difficulty in assessing them in a mid-trimester fetus. As far as we are aware, our case 2 seems to be the second example of distal 14q trisomy which was diagnosed prenatally (Wahlström, 1974).

The majority of the previously reported cases with distal $14 \mathrm{q}$ trisomy resulted from parental balanced translocations or pericentric inversions. Four cases occurred de novo: a tandem duplication in 3 cases (Nikolis et al., 1983; Orye et al., 1983; Carr et al., 1987) and an unbalanced translocation of the distal 14q segment onto the short arm of chromosome 10 in one case (Bridgman and Butler, 1980). Trisomic segments of the reported cases were varied, ranging from. q22 $\rightarrow$ qter to $\mathrm{q} 32 \rightarrow$ qter. To make specific karyotype-phenotype comparisons on the basis of length of $14 \mathrm{q}$, these cases were divided into three groups: 5 cases with trisomy for $14 \mathrm{q} 22$ or q23 $\rightarrow$ qter (Pfeiffer et al., 1973; Fryns et al., 1977; Bridgman and Butler, 1980; Geormaneanu et al., 1981; Cohen et al., 1983), 9 cases with trisomy for 14q24 $\rightarrow$ qter (Wyandt et al., 1977; Atkins and Patil, 1983; Nikolis et al., 1983; Orye et al., 1983; Romain et al., 1983; Kaiser et al., 1984; Markkanen et al., 1984; Sklower et al., 1984; Mikelsaar et al., 1987), and 5 cases with trisomy for $14 \mathrm{q} 31$ or $\mathrm{q} 32 \rightarrow \mathrm{qter}$ (Trunca and Opitz, 1977; Turleau et al., 1983; Sklower et al., 1984; Carr et al., 1987).

Clinical features of the three groups are summarized in Table 1. Intriguingly, the three groups have similar phenotypic features, except for incidence of early infant death and congenital heart disease. Common clinical features are growth retardation, mental retardation, microcephaly, facial asymmetry (this may be overlooked in many cases), frontal bossing, hypertelorism, sparse eyebrows and eyelashes, cupid 


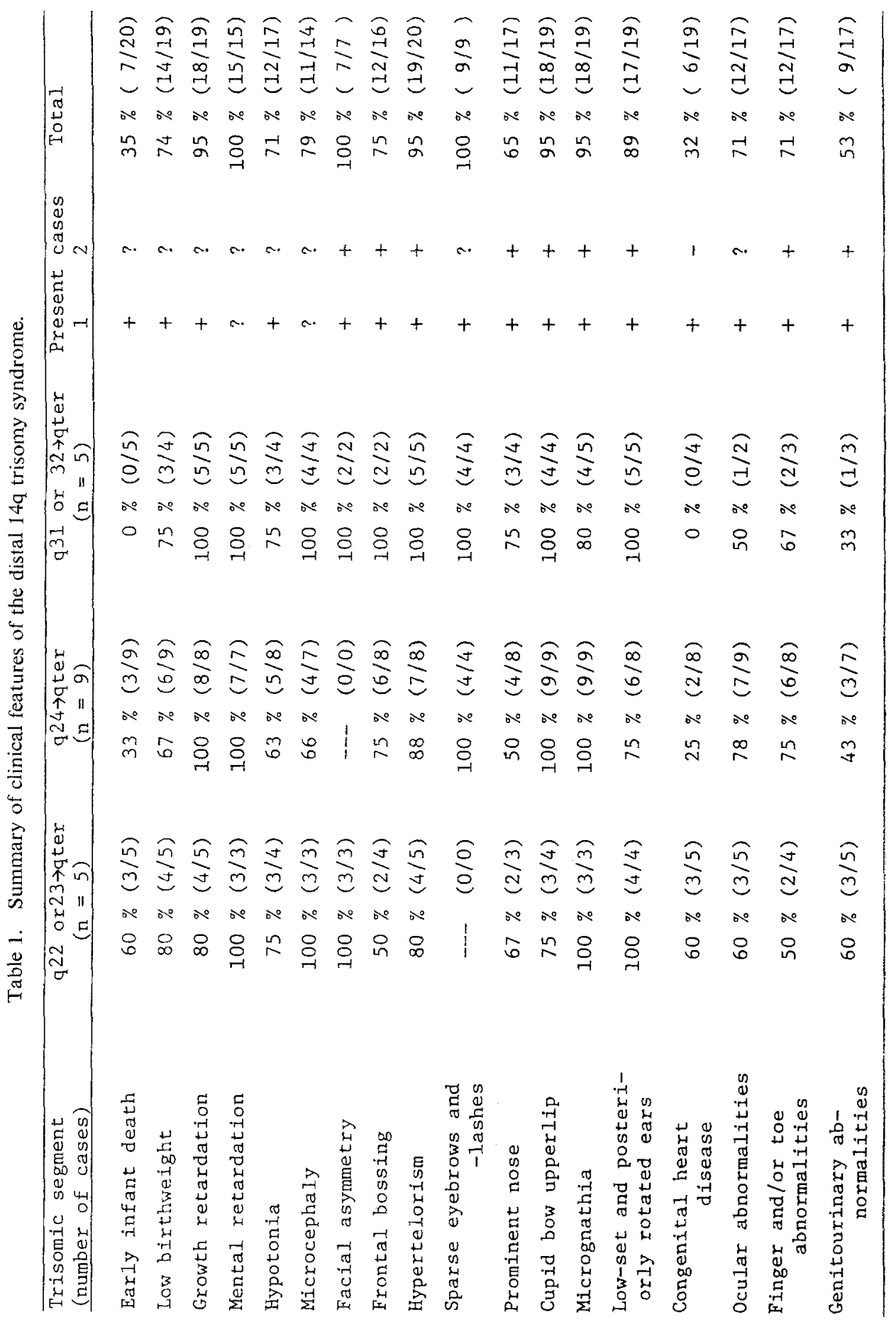


bow upperlip, micrognathia, and ear malformations. Although several of these are nonspecific features commonly seen in various chromosome aberrations, those such as facial asymmetry, sparse eyebrows and eyelashes, and cupid bow upperlip are rarely seen in other chromosomal syndromes (de Grouchy and Turleau, 1984; Schinzel, 1984). The constellation of such features permits us to recognize the distal $14 \mathrm{q}$ trisomy on a clinical basis alone. The full picture of the distal $14 \mathrm{q}$ trisomy syndrome in a case with trisomy for $14 \mathrm{q} 32.1 \rightarrow$ qter (Turleau et al., 1983) suggests that the triplication of the segment $14 \mathrm{q} 32.2 \rightarrow$ qter suffices to cause the syndrome.

Finally, it should be noted that cases with 14 trisomy mosaicism have many clinical features in common with those of the distal $14 \mathrm{q}$ trisomy syndrome but not with those of the proximal 14q trisomy syndrome (de Grouchy and Turleau, 1984). We believe that 'epistasis' of genetic materials in the distal $14 \mathrm{q}$ segment over those in the proximal $14 \mathrm{q}$ segment may be operating in clinical manifestation of the 14 trisomy mosaicism.

\section{REFERENCES}

Atkin, J.F. and Patil, S. 1983. Duplication of the distal segment of 14q. Am. J. Med. Genet. 16: 357-366.

Bridgman, G. and Butler, L.J. 1980. A child trisomic for the distal part of chromosome 14q. Arch. Dis. Child. 55: 474-477.

Carr, D.M., Quartey, K.J., Vartanian, M.V., and Kaplan, H.M. 1987. Duplication 14 (q31 $\rightarrow$ qter). J. Med. Genet. 24: 372-374.

Cohen, M.M., Charrow, J., Balkin, N.E., and Harris, C.J. 1983. Partial trisomy 14 (q23 $\rightarrow$ qter) via segregation of a $14 / \mathrm{X}$ translocation. Am. J. Hum. Genet. 35: 635-644.

Fryns, J.P., VanEygen, M., Tanghe, W., and Van den Berghe, H. 1977. Partial trisomy 14q due to familial $\mathrm{t}(14 \mathrm{q}-; 11 \mathrm{q}+)$ translocation. Hum. Genet. 37: 105-110.

Geormaneanu, M., Geormaneanu, C., Walter-Rosianu, A., and Papue, M. 1981. Trisomie 14q distale associeé a l'agenesie du corps calleux et au tronc arterial commun, due a la translocation maternelle $\mathrm{t}(5 ; 14)(\mathrm{q} 13 ; \mathrm{q} 23 \mathrm{q} 32)$. Ann. Génét. 24: 176-178.

Grouchy, J. de and Turleau, C. 1984. Clinical Atlas of Human Chromosomes, 2nd Ed., John Wiley and Sons, New York.

Ikeuchi, T. and Sasaki, M. 1979. Accumulation of early mitotic cells in ethidium bromide-treated human lymphocyte cultures. Proc. Jpn. Acad. 55: 15-18.

Kaiser, P., Förster, W., Steuernagel, P., Hillig, U., and Herberg, K.P. 1984. Familial pericentric inversion (14)(p11;q24) with a rec dup(q) in one offspring. Clin. Genet. 26: $73-76$.

Markkanen, A., Somer, M., and Nordström, A.M. 1984. Distal trisomy 14q syndrome; a case report. Clin. Genet. 26: 231-234.

Mikelsaar, V.A., Ilus, T.A., and Lurie, I.W. 1987. Distal trisomy 14q. J. Med. Genet. 24: 380381.

Nikolis, J., Ivanovic, K., and Kosnovic, M. 1983. Tandem duplication of chromosome 14 (q24 $\rightarrow$ q32) in male newborn with congenital malformations. Clin. Genet. 23: 321-324.

Orye, E., Van Bever, H., and Desimpel, H. 1983. Distal trisomy 14q due to tandem duplication (q24 $\rightarrow$ q32). Ann. Génét. 26: 238-239.

Pfeiffer, R.A., Buttinghaus, K., and Srtuck, H. 1973. Partial trisomy 14 following a balanced reciprocal translocation $\mathrm{t}(14 \mathrm{q}-; 21 \mathrm{q}+)$. Humangenetik 20 : 187-189.

Romain, D.R., Columbano-Green, L.M., and Smythe, R.H. 1983. Partial trisomy 14q24 $\rightarrow$ qterJ. Med. Genet. 20: 466-467. 
Schinzel, A. 1984. Catalogue of Unbalanced Chromosome Aberrations in Man. De Greuter, Berlin. Sklower, S., Tenkins, E., Nolin, S., Duncan, C.J., Warburton, D., Yeboa, K.A., Merkrebs, A., Schwartz, R., Wisniewski, K., Stimson, C., and Brown, W.T. 1984. Distal duplication 14q: Report of three cases and further delineation of the syndrome. Hum. Genet. 68: 159-164.

Trunca, C. and Opitz, J.M. 1977. Pericentric inversion of chromosome 14 and thr risk of partial duplication of 14q (14q31 $\rightarrow$ 14qter). Am. J. Med. Genet. 1: 217-228.

Turleau, C., Grouchy, J. de, Chavin-Colin, F., Denavit, M.F., and le Touze, P. 1983. Distal 14q trisomy. Ann. Génét. 26: 165-170.

Wahlström, J. 1974. A prenatally discovered unbalanced translocation $t(14 ; 22)(\mathrm{q} 22$ or $23 ; \mathrm{q} 13)$. Hereditas 78: 251-254.

Wyandt, H.E., Magenis, R.E., and Hecht, F. 1977. Abnormal chromosomes 14 and 15 in abortions, syndromes and malignancy. In New Chromosomal Syndromes, Yunis, J.J., ed., Academic Press, New York, pp. 304-314. 